\title{
The Sea Air Defense Combat Method Based on Graph Theory Design and Analysis
}

\author{
Zhang Xinjie \\ Department of Surface Ship Command, Dalian Naval \\ Academy, Dalian, 116018, China; \\ E-mail: mailbox1314@126.com
}

\begin{abstract}
According to the characteristics of modern air defense combat at sea, on the analysis of the "cooperative engagement capability (CEC)", on the basis of using the knowledge of graph theory, we design a maritime defense -small world network (WS), the connection between the network nodes is realized through communication link, finally, the network structure performance is analyzed. Research results to achieve real sea air defense combat network to provide certain reference and reference.
\end{abstract}

Keywords-Maritime Air Defense Combat; The Network Model; Graph Theory

\section{INTRODUCTION}

Sea fleet mission by various platforms (planes, ships and submarines) launch anti-ship missile threats, including air missiles, anti-radiation missiles, cruise missiles and tactical ballistic missiles, etc., the tf and the cruise missile is the biggest threat. Developed by the U.S. navy "cooperative engagement capability (CEC)," using the computer, communication and network technology, the sea fleet of the ship target detection system, command and control systems, weapon system and an organic network awacs systems, tf within a very short time delay is allowed to share the platform all the data obtained by the detection system, thus the whole fleet got behind a whole, can greatly increase the efficiency of the fleet of air defense missile defense. "Cooperative engagement capability (CEC)" is the "network centric warfare (clncw-2 under)" typical application in the navy. The article is based on graph theory to design a maritime defense network.

\section{A COMPLEX NETWORK OF RESEARCH WAS REVIEWED}

Complex networks since 1960 by Erdos and Renyi (ER) as a random network topology structure research, has been attracting the attention of people. A complex network of related models are:

Rules of network and stochastic network; Small world network (WS); Scale-free networks and other networks model.

\section{A. Statistical Feature of Complex Network of Network Parameters}

(1) the average path length

Complex network research, for a composed of $\mathrm{N}$ nodes in the network, I generally define two nodes, the

\author{
Ma Liang \\ Department of Surface Ship Command, Dalian Naval \\ Academy, Dalian, 116018, China; \\ E-mail: maliang2014@tom.com
}

distance between $l(\mathrm{i}, \mathrm{j})$ for the connection both the node number of the shortest path; The diameter of the network is the maximum distance between any two points; The average path length $l$ of the network is the average of the distance between all nodes on, it describes the degree of separation between the nodes in the network.

$$
\overline{\mathrm{l}}=\frac{1}{\mathrm{~N}} \sum_{\mathrm{i}=1}^{\mathrm{N}}\left[\frac{1}{\mathrm{~N}} \sum_{\mathrm{j}=1}^{\mathrm{N}} l(\mathrm{i}, \mathrm{j})\right]
$$

(2) Gathered Coefficient

Aggregation coefficient $\mathrm{C}$ is used to describe the gathering for nodes in the network, the network has more closely. The calculation method for: I assume that node by side connected to other nodes $\mathrm{k}_{\mathrm{i}}$, if the nodes $\mathrm{k}_{\mathrm{i}}$ are interconnected, they should exist between $\mathrm{k}_{\mathrm{i}}\left(\mathrm{k}_{\mathrm{i}}-1\right) / 2$ side, while the actual number of edges between nodes $\mathrm{k}_{\mathrm{i}}$ only have $\mathrm{E}_{\mathrm{i}}$, that $\mathrm{k}_{\mathrm{i}}\left(\mathrm{k}_{\mathrm{i}}-1\right) / 2$ is the aggregation coefficient of node $i$, namely:

$$
\mathrm{C}_{\mathrm{i}}=\frac{2 \mathrm{E}_{\mathrm{i}}}{\mathrm{k}_{\mathrm{i}}\left(\mathrm{k}_{\mathrm{i}}-1\right)}
$$

Network clustering coefficient are the average aggregation coefficient of all the nodes in the network. Obviously, only in the total network (each node is connected to the rest of the all nodes), aggregation coefficient is equal to 1 , generally less than 1 .

3) Degree Distribution

i nodes in graph theory for the node I connect the edge of the total number of all the nodes i referred to as a network of the average degrees $\mathrm{k}_{\mathrm{i}}$, defined as $\langle\mathrm{k}\rangle$. Network node degree distribution with the distribution function $\mathrm{P}(\mathrm{k})$, its meaning is an arbitrary choice of the probability of nodes are well $\mathrm{k}$ edge, is equal to the number of degrees of $\mathrm{k}$ nodes in the network of the ratio of the total number of network nodes.

4) Betweenness

Betweenness is divided into edge betweenness and node betweenness. Node betweenness for all the shortest path in the network after the node number in proportion; The edge betweenness has similar meanings. The 
corresponding node or edge betweenness reflect in the role and influence in the whole network.

\section{B. Assumptions}

Maritime defense network the key to improve the air defense missile operational effectiveness is: improve the ability of real-time information sharing, improve the ability of multi-objective interception, implements the centralized type of ship to air missile command and overthe-horizon interception, then expand the ship to air missile combat area.

Maritime defense network design, the following assumptions:

1) In the network node number is limited, $\mathrm{n} \leq \mathrm{M}$. $\mathrm{M}$ as an integer, such as $\mathrm{M}=10$;

2) In the network node implementations of relay communication ability is limited, can't unlimited relay communication services, the degree of a node is limited;

\section{Network Design}

Reference design idea of CEC system network structure, on maritime defense network design:

1) For the rapid information sharing ability (namely small world, the smaller the shortest path) and the perturbation resistance strong random attack (i.e. larger clusters, relatively large aggregation coefficient, small world network model is used to build (as shown in figure $1)$;

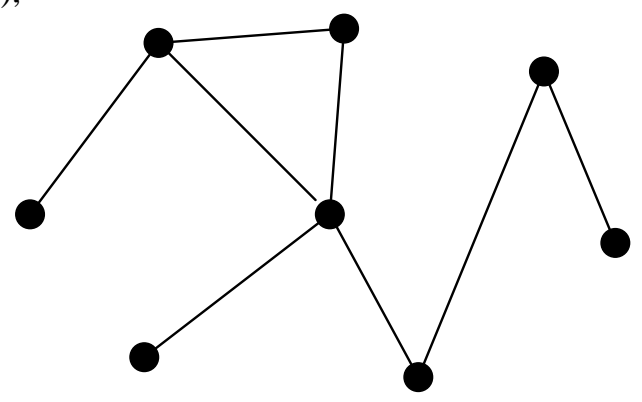

Figure 1. Sea Air Defense Combat Effectiveness Node

2) to improve the efficiency of the accused node command, accused of nodes in the network of 1 - the center of gravity;

3) to improve the survivability of the network, the current allegations center nodes were destroyed, a standby charges under the network automatically enabled center.

4) in order to ensure the communication between nodes in a network connectivity, accused of nodes using the algorithm of dynamic restructuring, to ensure that when a member node and charges cannot be established communication link, can with a backup charges node communication link is established.

\section{NETWORK PERFORMANCE ANALYSIS}

\section{A. the Execution Time}

Now suppose there is a composed of command and control node in the network is used to coordinate a key time. The nodes of each node to complete several information processing tasks. If $\lambda_{i}$ for the node $i$ completed all of its mission, the average length of time of complete the task are assumed to be exponential distribution, in this way, $\mathrm{F}_{\mathrm{i}}(\mathrm{t})$ for accomplishing all tasks in a node $\mathrm{i}$ at time $\mathrm{t}$.

$$
F_{i}(t)= \begin{cases}1-e^{-t / \lambda_{i}} & t>0 \\ 0 & t \leq 0\end{cases}
$$

Generally speaking, in the network to support the action will have several parallel and sequential node. A total of $\mathrm{M}$ has such a function set of nodes. In the simplest case, a critical path consists of $\mathrm{N}$ nodes, where $\mathrm{N}$ is a subset of $\mathrm{M}$, as shown in figure 2 .

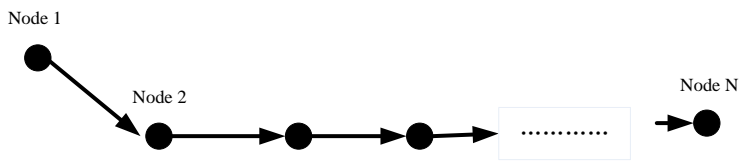

Figure 2. the Key Path

Define the critical path the total execution time for the path waiting time (time), the sum of all nodes plus terminal firing weapons and target in time. In the case of the sequential, the total time is the critical path is supposed to be performed on the expectation of node execution time plus the sum of time:

$$
\mathrm{T}=\sum_{\mathrm{i}=1}^{\mathrm{N}} \lambda_{\mathrm{i}}+\mathrm{t}_{\mathrm{m}}
$$

If there are both node serial and parallel on the critical path node, as shown in the following ways to illustrate the means of processing.

In figure 3 this example are as follows:

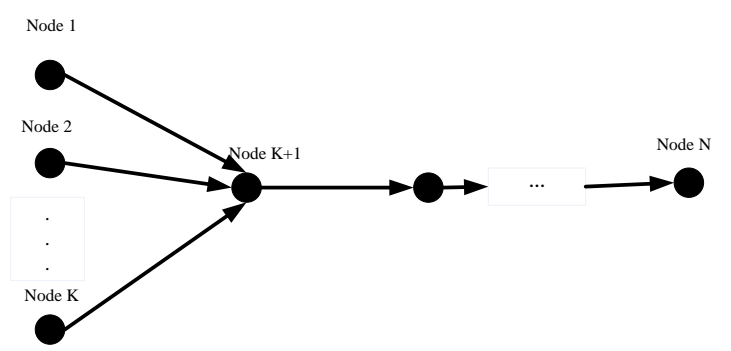

Figure 3. Parallel Node of the Critical Path

$\mathrm{T}=\max \left(\lambda_{1}, \lambda_{2}, \cdots, \lambda_{\mathrm{k}}\right)+\lambda_{\mathrm{k}+1}+\cdots+\lambda_{\mathrm{N}}+\mathrm{t}_{\mathrm{m}} 4-3$

The article's centre of gravity is not refers to the geometric center of the network, but to achieve a certain performance or efficiency (e.g., shortest transmission delay) and determine a network node. In this paper, we will charge the node as the center of gravity of the network, in order to realize rapid information sharing ability and strong random disturbance resistance. The following discussion network the center of gravity of the problem.

Has undirected networks $\mathrm{N}=(\mathrm{V}, \mathrm{E}, \mathrm{W}, \mathrm{Q})$, including $\mathrm{W}$ for edge weights, distance or length, $\mathrm{W}=\left\{\omega_{\mathrm{ij}}\right\}(\mathrm{i}, \mathrm{j}) \in \mathrm{E}$ commonly, $\mathrm{Q}$ for weights on the 
vertices, $Q=\left\{q_{i}\right\}$ and the $q_{i}$ corresponding vertex weights $\mathrm{V}_{\mathrm{i}}$. The network can be expressed as the center of gravity of the problem

$$
\min _{z} M(z)=\sum_{i} q_{i} d(z, i)
$$

$\mathrm{d}(\mathrm{z}, \mathrm{i})$ is the network from $\mathrm{z}$ to the vertices $\mathrm{v}_{\mathrm{i}}$ of the short circuit. $Z$ may be on the network vertices, may also be one side between the peaks, is determined by the shortest path; Like in the $\mathrm{z}$ is located in the edge $(\mathrm{a}, \mathrm{b})$, and the proportion of center point a, is $\theta$, that

$$
\mathrm{d}(\mathrm{z}, \mathrm{i})=\min \left\{\theta \mathrm{d}_{\mathrm{ba}}+\mathrm{d}(\mathrm{a}, \mathrm{i}),(1-\theta) \mathrm{d}_{\mathrm{ab}}+\mathrm{d}(\mathrm{b}, \mathrm{i})\right\}
$$

If the network as directed, for the network $(a, b)$ in an arc, then $\mathrm{d}_{\mathrm{ba}}=\infty$, type the first you can skip some consider at this time.

With $\mathrm{N}$ to the network, the edge of $\mathrm{Z}^{*}$ have a point $(a, b), V_{A}$ is the vertex $v_{i}$ to $z^{*}$ the shortest path through the vertices of a collection of all the vertices $v_{i}$. Unless a vertex $\mathrm{z}^{*}$ to the shortest path through a (that is, through $b$ ), then the vertices do not belong to $V_{A}$, and to belong to $\mathrm{V}_{\mathrm{B}}$, so:

$$
\mathrm{V}_{\mathrm{A}} \cup \mathrm{V}_{\mathrm{B}}=\mathrm{V}, \quad \mathrm{V}_{\mathrm{B}}=\mathrm{V} \backslash \mathrm{V}_{\mathrm{A}}
$$

Thus there are

$$
\begin{aligned}
& \mathrm{M}\left(\mathrm{z}^{*}\right)=\sum_{\mathrm{i} \in \mathrm{V}_{\mathrm{A}}} \mathrm{q}_{\mathrm{i}} \mathrm{d}\left(\mathrm{z}^{*}, \mathrm{i}\right)+\sum_{\mathrm{i} \in \mathrm{V}_{\mathrm{B}}} \mathrm{q}_{\mathrm{i}} \mathrm{d}\left(\mathrm{z}^{*}, \mathrm{i}\right) \\
& =\sum_{\mathrm{i} \in \mathrm{V}_{\mathrm{A}}} \mathrm{q}_{\mathrm{i}}\left[\mathrm{d}(\mathrm{a}, \mathrm{i})+\theta \mathrm{d}_{\mathrm{ba}}\right]+\sum_{\mathrm{i} \in \mathrm{V}_{\mathrm{B}}} \mathrm{q}_{\mathrm{i}}\left[\mathrm{d}(\mathrm{b}, \mathrm{i})+(1-\theta) \mathrm{d}_{\mathrm{ab}}\right] \\
& =\theta\left\{\sum_{\mathrm{i} \in \mathrm{V}_{\mathrm{A}}} \mathrm{q}_{\mathrm{i}}\left[\mathrm{d}(\mathrm{a}, \mathrm{i})+\mathrm{d}_{\mathrm{ab}}\right]+\sum_{\mathrm{i} \in \mathrm{V}_{\mathrm{B}}} \mathrm{q}_{\mathrm{i}} \mathrm{d}(\mathrm{b}, \mathrm{i})\right\} \\
& +(1-\theta)\left\{\sum_{\mathrm{i} \in \mathrm{V}_{\mathrm{A}}} \mathrm{q}_{\mathrm{i}} \mathrm{d}(\mathrm{a}, \mathrm{i})+\sum_{\mathrm{i} \in \mathrm{V}_{\mathrm{B}}} \mathrm{q}_{\mathrm{i}}\left[\mathrm{d}(\mathrm{b}, \mathrm{i})+\mathrm{d}_{\mathrm{ab}}\right]\right\}
\end{aligned}
$$

By the relation

$$
\begin{aligned}
& \mathrm{d}(\mathrm{a}, \mathrm{i})+\mathrm{d}_{\mathrm{ab}} \geq \mathrm{d}(\mathrm{b}, \mathrm{i}) \\
& \mathrm{d}(\mathrm{b}, \mathrm{i})+\mathrm{d}_{\mathrm{ab}} \geq \mathrm{d}(\mathrm{a}, \mathrm{i}) \\
& \quad \mathrm{M}\left(\mathrm{z}^{*}\right) \geq \theta \sum_{\mathrm{i} \in \mathrm{V}} \mathrm{q}_{\mathrm{i}} \mathrm{d}(\mathrm{b}, \mathrm{i})+(1-\theta) \sum_{\mathrm{i} \in \mathrm{V}} \mathrm{q}_{\mathrm{i}} \mathrm{d}(\mathrm{a}, \mathrm{i}) \\
& \quad=\theta \mathrm{M}(\mathrm{b})+(1-\theta) \mathrm{M}(\mathrm{a})
\end{aligned}
$$

As a result, there will be $\mathrm{M}(\mathrm{a}) \leq \mathrm{M}\left(\mathrm{z}^{*}\right)$ or $\mathrm{M}(\mathrm{b}) \leq \mathrm{M}\left(\mathrm{z}^{*}\right)$, for any $\mathrm{z}^{*}$, there is always a vertex. $i^{*}$ the center of gravity of the optimal solution which indicate that the network often one vertex in the network. Also suggests that each node in the maritime defense network exists in a satisfied optimal command and control tasks (rapid information sharing ability and strong random disturbance resistance) of the node, the node is the center of gravity of the network.

\section{B. Ability to Survive}

Discussed in this paper, the network survivability the maritime air defense network structure of connected ability oneself, does not include the anti-damage ability of each node, the kill probability, etc.

By the knowledge of graph theory, the connectivity can be used to measure the strength of a connected graph, it shows how much a figure at least remove the edge or vertex cannot destroy the connectivity, or, can remove most figure of how many edges or vertex connectivity can remain. Figure two parameters are available "connectivity" and "connectivity" to reflect the size of the figure of connecting strength. Connectivity and edge connectivity, the greater the network more reliable. In this paper, through the discussion of "connectivity" to study the connecting ability of the network.

Equipped with air defense network diagram $G=(V, E), V$ for the node set, $E$ for edge set, the following research, any two nodes in the network $S$ network connectivity probability between $\mathrm{T}$.

There are $\mathrm{k}$ path between node $\mathrm{A}$ and node $\mathrm{S}$, and the path $\mathrm{i}$ connected probability is $\mathrm{A}_{\mathrm{i}}(\mathrm{i}=1,2 \cdots \mathrm{k})$, expressed in A node $\mathrm{S}$, T connectivity.

Path between a node $\mathrm{S}, \mathrm{T}, \mathrm{k}$, if and only if at least one path connecting the two nodes are interconnected, it is

$$
\mathrm{A}=\mathrm{A}_{1} \cup \mathrm{A}_{2} \cup \cdots \cup \mathrm{A}_{\mathrm{k}}
$$

Nodes are obtained by the independence of the events, $S$, T between the connected probability:

$$
\begin{aligned}
& P(A)=P\left(A_{1} \cup A_{2} \cup \cdots \cup A_{k}\right) \\
& =\sum_{i=1}^{k} P\left(A_{i}\right)-\sum_{i<j<k}^{k} P\left(A_{i} A_{j}\right)+\cdots+(-1)^{k-1} P\left(A_{1} A_{2} \cdots A_{k}\right) \\
& P\left(A_{1} A_{2} \cdots A_{k}\right)=P\left(A_{i}\right) P\left(A_{2}\right) \cdots P\left(A_{k}\right)
\end{aligned}
$$$$
\text { Type: } \mathrm{A}_{\mathrm{i}}=\mathrm{L}_{\mathrm{i} 1} \mathrm{~L}_{\mathrm{i} 2} \cdots \mathrm{L}_{\mathrm{ij}} \in \mathrm{E} ; \mathrm{L}_{\mathrm{ij}} \text { is the first article }
$$
I path $\mathrm{j}$ article links

$$
\mathrm{P}\left(\mathrm{A}_{\mathrm{i}}\right)=\mathrm{P}\left(\mathrm{L}_{\mathrm{i} 1} \mathrm{~L}_{\mathrm{i} 2} \cdots \mathrm{L}_{\mathrm{ij}}\right)=\mathrm{P}\left(\mathrm{L}_{\mathrm{i} 1}\right) \mathrm{P}\left(\mathrm{L}_{\mathrm{i} 2}\right) \cdots \mathrm{P}\left(\mathrm{L}_{\mathrm{ij}}\right)
$$

$\mathrm{P}\left(\mathrm{L}_{\mathrm{ij}}\right)$ Article $\mathrm{j}$ said in the first article $\mathrm{i}$ path link connectivity probability.

The reliability of the link between the available link connectivity probability reflects, link failure rate are assumed to be exponential distribution, are:

$$
\mathrm{P}(\mathrm{t})= \begin{cases}1-\mathrm{e}^{-\mathrm{t} / \theta_{\mathrm{j}}} & t>0 \\ 0 & t \leq 0\end{cases}
$$

Therefore, the reliability of the link

$$
\mathrm{Q}=1-\mathrm{P}(\mathrm{t})
$$

\section{CONCLUSION}

Maritime defense network by the detector, charge network and weapon network, the network is an organic whole repeatedly through the communication system. Article on the basis of graph theory, we design a maritime defense network model -- small world network, the network connection is through the communication link between. Articles not discussed the performance of network node itself, and the main structural characteristics are studied for the networks themselves. For maritime air defense combat network, the network 
structure is the precondition of network warfare. To establish a real sea air defense network, there are many technical problems need to study, such as space and time consistency technology, command and control function of dynamic reconfiguration technology, collaborative guidance technology, point trace synthesis and information fusion technology, etc.

\section{REFERENCES}

[1] Lazarus E. The application of value-driven decision-making in air combat simulation[C]. Proceedings of 1997 IEEE International Conference on System,Man,and Cybernetics and Computational Cybernetics and Simulation, Piscataway,NJ, 1997: IEEE Press: 2302-2307.

[2] A.Hadi-Vencheh, M.Allame. On the relation between a fuzzy number and its centroid [J].Comput. Math. Appl, 2010, 59: 3578-3582

[3] Liang Bo, Duan Ran.Fire distribution model based on feasible direction algorithm $[\mathrm{J}]$, Command Information System and Technology, 2013,4 (2) : 30-32

[4] WANG Hong-jun, CHI Zhong-xian.Shipboard hard and soft weapon anti-missile decision-makingoptimization based on collaboration[J], Control and Decision, 2007, 22 (3) : 299303

[5] Sarit Kraus.Negotiation and cooperation in mulfi-ageat environments.Artificial Intelligence. $1997:$ 79-97

[6] HUANG Haixin, WANG Ding wei.English auction dynamic model based on fuzzy game[J], Information and Control,2012,41(4):509-513

[7] Shao Qiu feng, Ma ya long, hu jin chuan.Applied research for fuzzy composite operators in operational alternatives integrated evaluation[J],Journal of Academy of Armored Force Engineering, 2004, 18 (12) : 41-43

[8] MA Liang, QING Zuo-sheng, ZHANG Lin.Formation comprehensive cooperative air defense multi-stage decision optimization modeling[J], Tactical Missile Technology, 2013,9 (5) $: 25-28$
[9] LIU Wei dong, JIANG Qing shan, LI Yong.Fire distribution of the network centric ship-to-air missile based on earlier damage[J],Ship Science And Technology, 2011,33 (2) : :98-101

[10] CHEN Guo sheng,JIA Zi ying.Research on coordinated air defense firepower distribution model for warships $[\mathrm{J}]$, Command ControI\& Simulation, 2011,33 (12) :13-15

[11] XU Z S. Multiple-attribute group decision making with different formats of preference information on attributes [J]. IEEE Trans on System, Man, and Cybernetics-Part B: Cybernetics, 2007, 37 (6) : 1500-1511.

[12] Lee Z J, Su S F, Lee C Y. Efficiently solving general weapontarget assignment problem by genetic algorithms with greedy eugenics [J].IEEE Transactions on Systems, Man and CyberneticsPartB, 2003, 33 (1)113-121.

[13] Abdollah, Mahdi. Seclusion-Factor Method to solve fuzzymultiple criteria decision-making problems [J].IEEE Trans on Fuzzy Systems, 2011, 19 (2): 201-209.

[14] Beynon M J, Bruce Curry, Peter Morgan. The Dempster-Shafer theory of evidence: An alternative approach to multi-criteria decision modeling $[\mathrm{J}]$. Omega, 2000, 28(1):37-50.

[15] Beynon M J. DS/AHP method: A mathematical analysis,including an understanding of uncertainty[J]. European $\mathrm{J}$ of Operational Research, 2002, 140(1): 148-164.

[16] Jong Seo Hwang. Analysis of effectiveness of CEC (Cooperative Engagement Capability) Using Schutzer' s C2 Theory [D] Monterey: Naval Postgranduate School, 2003.

[17] Johns Hopkins. The cooperative Engagement Capability [J]. APL Technical Digest, 1995, 16(4): 377-395.

[18] David S Alberts, John J Garstka. Understand Information Age Warfare [M]. CCRP publication series, 2001: 21-142.

[19] James Moffat. Complexity Theory and Network Centric Warfare [M]. CCRP publication series, 2003: 22-109.

[20] David S. Alberts, John J. Garstka. Frederick P.Stein.Network Centric Warfare:Developing and Leveraging Information Superiority[M]. CCRP publication series, 2000: 19-186.

[21] William D. O'Neil. The Cooperative Engagement Capability (CEC) Transforming Naval 